\title{
A Review for Digitalization of the Process Landscape for Proprietary Bond Trading
}

\author{
Timothy Petrov ${ }^{1}$, Wolfgang Neussner ${ }^{1,}{ }^{*}$, Maximilian Lackner ${ }^{1}$ \\ ${ }^{1}$ University of Applied Sciences Technikum Wien, Höchstädtplatz 6, 1200 Wien, Austria \\ *corresponding author: neussner@technikum-wien.at
}

\begin{abstract}
On the surface, the process landscape for fixed income securities trading within most banks has changed only slightly in the past four decades. The value chain remains divided amongst front-, middle-, and back office, with IT in support. Front office negotiates deals with customers and other banks, middle office manages risks and reporting, and back office ensures that payments are made in exchange for a transfer of the bonds that have been traded. Though these processes have gradually migrated to electronic mediums, much of the work in all functional areas remains manual. But the advent of digital technologies, primarily process automation software and data integration in an open software architecture, allows banks to dramatically change how the processes along the value chain are carried out. Repetitive and predictable tasks can be performed by automated software, allowing humans to concentrate on complex activities that require flexibility and discretion. Those tasks that remain in the hands of humans can also be made more efficient by extracting data from software applications along the entire process chain and providing them to the human user at the right point in time in the right system.

This research paper analyzes the end-to-end bond trading processes within European banks, examines the key performance indicators that measure the performance of each operational area, and poses the question how digitalization can improve these same KPIs. Research for the paper was conducted by interviewing functional experts from a European bank and also experts from an IT service provider regarding the process landscape for bond trading and the technologies that are available for reshaping this landscape. Across all functional areas, the research shows that the level of process automation that could be achieved is extraordinarily high, approaching 100 percent. But the research also reveals factors, such as cost, quality, and a negative impact on a bank's trading profits, which effectively limit the practical automation rate to a lower level. Having identified the KPIs in each functional area, as well as the factors that limit their optimization, the paper establishes not only quantitative goals but also a qualitative roadmap for how banks can proceed in optimizing their business processes and the IT landscape that supports them.
\end{abstract}

Keywords. Digitalization, process automation, data integration, securities trading, process landscape.

\section{Introduction}

The past decade-plus since the 2008 financial crisis has been a difficult period for banks, and perhaps nowhere more so than in Europe. The collapse of the brokerage Lehman Brothers in September 2008 triggered a crisis in the United States that quickly spread internationally and threatened to wipe out a large portion of the banking sector in many Western countries. In Europe, this was followed just two years later by the start of a sovereign debt crisis in Greece, which threatened to spill over into both the European banking sector and to other sovereign nations with low credit ratings, such as Portugal, Italy, 
and Spain. Consequences as severe as the bankruptcy of multiple sovereign states, the destruction of the European financial sector, and even the dissolution of the European Union (EU) threatened. In both crises, the worst-case scenarios were averted by decisive action by state and, in the case of Europe, supranational institutions. The emergency measures fell into two categories: direct state capital in the form of bailout funds, and additional liquidity from central banks in the form of asset purchases and lower interest rates. The logic behind both measures was relatively straight-forward. Bailouts were intended to supply capital to entities - either banks or sovereign nations - that were threatened by bankruptcy. And the lowering of interest rates was meant to reduce the borrowing costs for those same banks or sovereign states, making it easier to pay the interest on their debt. Besides the direct benefits, both types of measures were intended to restore faith in a financial system that relies to a large extent on the faith of its participants (Laffan, 2015).

The consequences for the business model of a bank are serious. A typical bank earns much of its profit from the difference in interest rates at which it borrows and lends. A bank lends - whether to corporate borrowers, in the form of corporate loans or securities, or to individual persons, in the form of personal loans or mortgages - at a higher rate than it borrows, either through deposits in savings accounts or by issuing its own fixed income debt securities. As the central banks lower their own lending rates, this ripples out through the entire financial system. Savers receive lower interest rates in their savings accounts, but borrowers of a mortgage on a home also pay lower interest rates. Critically for a bank, the difference between the two rates also tends to fall, resulting in lower profit margins for the bank (Covas, et al., 2015).

As interest rates have remained suppressed, pressure to cut costs in fixed income operations has remained high. Fixed income markets have long been fragmented and intransparent, with high costs for processes along the entire process chain. Whereas other securities, such as equities, have long been traded on regulated exchanges, where buyers and sellers come together in a relatively efficient process, fixed income markets have traditionally been so called Over-the-Counter (OTC) markets, where individual buyers and sellers approach each other outside of the framework of an exchange. This means that not only the execution of trades, but also the settlement process, where one party pays for the purchase and the other transfers the securities, are also inefficient compared to an exchange. Large portions of the process chain have long been digitized, with paper trade tickets and physical delivery of the securities replaced by electronic records and only a virtual electronic delivery from one custodial account to another, but for many banks a significant portion of the processes is still performed manually (Tyce \& Tang, 2020).

New software technologies offer the possibility to change this. Cloud computing allows better integration of and access to data, and machine learning software can use this data to take a large number of inputs, perform a repetitive process, and create outputs. In this manner, routine tasks can be automated, freeing up human users to solve problems or monitor the processes for consistency and stability. The potential benefits to a bank that can integrate such new technologies into a digitalized process landscape are significant. Not only lower costs, but also lower risk, faster passthrough times, and better customer service can be expected (Dean, 2014).

This research paper will examine the existing process landscape for European banks that trade fixed income securities on a proprietary basis, and it will analyze the potential impact of technologies such as machine learning, automated software, and data integration on this process landscape. The research will be in the form of expert interviews conducted with both functional and IT experts, whose combined expertise covers the entire process landscape of proprietary fixed income trading, clearing, and settlement. Their views and opinions will be used to form hypotheses regarding the impact of the independent variables listed above on the performance of the bank's bond trading business in different operational areas.

Performance in each operational area must be defined in the form of one or more Key Performance Indicators (KPI), so that it can be measured or estimated quantitatively. These KPIs will be ascertained in the expert interviews, and the hypotheses formed in this research paper will attempt to answer the following questions:

1. Beyond the profit or loss in an organization's bottom line, which KPIs can be used to measure the performance of a bank's proprietary bond trading organizational units?

2. Which processes or subprocesses in front, middle, and back office, as well as in IT, can be optimized by the application of digital technologies 
3. What is a reasonable expectation for the impact on the KPIs through their application?

\section{Theory}

The following pages establish a baseline for proprietary bond trading by European investment banks. This is the framework into which the research questions above will be placed. The available digital technologies that can be applied to the bond trading process landscape will then be summarized.

\subsection{Bonds and the Secondary Market}

A bond is a debt instrument that is sold by an entity, including governments, government-backed agencies, or corporations, in order to raise capital from a wide spectrum of investors. The process of selling a new bond to investors is known as issuance, with the entity that wants to raise capital known as the issuer of the bond Once the security has been issued, the issuer pays a series of predetermined interest or dividend payments to the owner and until the security reaches a predetermined maturity date. Once the security reaches maturity, the owner is repaid the notional or principal amount of the debt by the issuer. (Francisco, 2012).

The basic principles of borrowing funds and repaying them on a fixed schedule at a predetermined rate are not unique to bonds. A bank loan, either to a corporation or to an individual for the purchase of a home or an automobile, is based on the same principles. The interest rate on the loan may be floating meaning it moves up or down over time based on a benchmark interest rate in the credit market - rather than fixed, but the basics of how a bond works are not dissimilar. But unlike many forms of debt, bonds can be sold to an unlimited number of investors. A bank loan may be made by a single bank or a syndicate of banks to a corporation or individual, but once the loan has been made, it is typically held by the syndicate of banks until maturity or sold to other institutional investors. The average retail investor private persons investing for themselves - will not typically be permitted to buy a portion of the loan. But with a bond issuance, any investor - from the underwriters to a pension fund, hedge fund, or individuals investing on their own behalf - is permitted to purchase the security. When a new bond is issued and sold by the issuer to investors with the help of the underwriting syndicate, this is known as the primary market. The underwriters coordinate the sale to other institutional or retail investors, and they agree to buy a portion of the bond issue itself. Once the new bond has been issued, the initial purchasers may sell to other investors in what is known as the secondary market. This secondary market, and the role that banks play in it, is the focus of this research paper (Iannotta, 2010).

The core function of an investment bank has traditionally been underwriting. An underwriter assists an issuer of a bond or equity in finding investors to buy the new issue. The underwriter takes on risk by promising to purchase the remainder of the issue if not enough investors can be found. Historically, the first bonds to be issued in this manner were government bonds, though corporate bonds issues gradually became common over the last few centuries, as well, so that corporate and sovereign bond markets are both large and diverse today. Investment banking has also involved over time, and modern investment banks undertake a wider variety of activities than just underwriting. These often include advisory services, proprietary trading, brokerage, or asset management (Iannotta, 2010).

Proprietary trading is defined as the buying or selling - or dealing - of securities in the bank's own name, using the bank's own funds. It stands in contrast to brokerage activities, where a bank trades in the name of a customer using the customer's funds. Institutions that perform both functions are often referred to as broker-dealers. Proprietary trading is considered an investment banking activity, and it is often closely tied to underwriting in a bank's organizational structure. The same investors who are likely to have interest in new bond issues in the primary market may also have interest in purchasing existing bonds directly from the bank in the secondary market. Proprietary trading is, therefore, a secondary market activity that is complimentary to underwriting activities in the primary market (Iannotta, 2010). In the secondary market, investor information is not equal, and the lack of information, together with preferences of different investors for certain bond maturities can lead to unexpected behavior in bond prices. In this fragmented and opaque market, relationships often offer a critical advantage, both for investors looking to purchase appropriate bond issues or sell their current holdings and for investment banks looking for buyers for upcoming primary market auctions or trying to actively trade bonds for short-term profit in the secondary market. A strong relationship is often an information exchange, with each side providing the other with valuable data about what bonds have been purchased or sold or are likely to be traded. Investment banks often separate the role of the trader, who determines whether the bank is willing to buy or sell a bond, as well as the amount and the price, from the role of a salesperson, 
whose function is to maintain contact with institutional investors, in order to learn which bonds they may have interest in (Mobius, 2012).

As the bond markets of Europe and the US have matured over the past half-century, the different roles played by investors and investment banks have crystalized into the concepts of a distinct "buy-side" and a "sell-side". The buy-side represents investors, generally fund managers, whether for a hedge fund, mutual fund, pension fund, or other asset manager. The sell-side includes banks, acting as dealers, which try to earn the business of the buy-side. The role of a dealer consists of mainly informal expectations by the dealer's buy-side customers. In the secondary market, with few exceptions, there is generally no legal requirement for a dealer to stand ready to provide a price for a bond, should a customer request one, rather the dealer is incentivized to provide prices in order to win business, and because the dealer's reputation will suffer, if too many requests are ignored or rejected. But the role of a dealer, and the accompanying expectation to provide prices upon request, can be formalized into a legal obligation in the form of a market making agreement. A dealer entering into a market making agreement with a securities exchange or other trading venue agrees to quote a security actively for a certain percentage of the time, often with a maximum bid-ask spread, meaning the price at which the dealer is willing to buy and the price at which the dealer is willing to sell may not be too far apart. Narrow spreads induce other market participants to become active in the market (Ho \& Macris, 2003).

Fixed income securities trading has evolved from its origins as a means for speculators or investors to trade a small number of government bonds to become a complex, varied market with a myriad of financial instruments and market participants. A look at the 2019 Annual Report of the US bank JP Morgan shows the significance of fixed income trading to the bank. In 2019, the division Fixed Income Markets brought in 14.4 billion USD in revenue, compared to just 6.4 billion USD for the division Equities Markets or 7.2 billion USD for all investment banking activities. This accounts for more than a third of the entire revenue of the Corporate and Investment Bank, the second largest of JP Morgan's four business lines. In this context, fixed income trading should be seen as one of the strategic pillars of one of the world's largest banks by assets. JP Morgan's 2019 Annual Report makes note of the different product lines that constitute the Fixed Income Market's business. Securitized products, credit markets, and rates markets are the three product lines within the division (JP Morgan Chase \& Co, 2020).

The current structure of the secondary market for bonds in Europe is, to a large extent, the result of the Global Financial Crisis of 2008. The causes of this credit crisis that shocked the global financial system are varied and complex. Even defining a starting date to the crisis is difficult. There were warning signs over the course of 2007, significantly the decline of the US housing market, to which an enormous amount of securitized debt was tied. The S\&P Case-Shiller US National Home Price Index, which tracks home prices in 20 major US markets and also nationally, reached an all-time high of 184.6 in July 2006. By December 2007, it had declined to 173.3, registering 17 straight months of declines. This decline was unprecedented since the Fed began tracking US housing prices in 1987. Although the relative decline in home prices was still under 10 percent at the end of 2007, it still had major implications for the broader US economy and for the financial markets, due to the fact that many banks and brokerages were using extremely high leverage at the time.

The collapse of the US brokerages Bear Stearns and Lehman Brothers may have been triggers, or perhaps accelerants, of the crisis, but they were not the root causes. Indeed, other investment banks and brokerages had collapsed over the decades without triggering a contagion that threatened to destroy the whole financial system. For example, the investment banks Salomon Brothers had very publicly gone from having one of the most profitable trading divisions in the world to the brink of collapse over a scandal in its bond trading unit barely a decade prior to Lehman Brothers' collapse. Eventually Salomon Brothers was bought by Travelers Group and became part of CitiGroup in 1998. But this forced takeover did not cause the remaining banks and brokerage houses in the credit market and rates market to cease lending to each other, as was the case in 2008 (Mayer \& Karpis, 1993).

A report presented by the Chairman of the US Securities and Exchange Commission (SEC), Mary Schapiro, to the House Financial Services Committee in 2010 detailed the causes of what became known as the Global Financial Crisis (GFC) in the opinion of the chief market regulator in the US. Some of the points that Schapiro presented - an "excessive reliance on credit ratings" of the ratings agencies or "compensation arrangements that encouraged excessive risk-taking" - are secondary, or even peripheral issues. But four other causes are presented in the report, which were deemed as having been central to creating the crisis. These are: widespread "irresponsible lending practices, which were facilitated by [the] securitization process"; the "proliferation of complex financial products, including 
derivatives...that were not fully transparent or understood" by the dealers trading them; a "financial regulatory framework that lacked the ability to monitor and reduce risks," coupled with an "inadequate appreciation of the risks of deregulation"; and an excessive amount of leverage by many banks and brokerages (Schapiro, 2010).

Though the crisis had its origins in America, it quickly spread internationally. Contagion from the US to Europe occurred via derivatives products, including IRS and CDS, as well as via the interbank shortterm lending markets, including LIBOR, EURIBOR, and the repo markets. European banks and investors had also purchased large amounts of securitized US products, and, just like their American counterparts, many did not appreciate the level of risk involved with those assets until the crisis had escalated. Though there was no spectacular single event in Europe such as the collapse of Lehman Brothers to symbolize the crisis, the financial losses, systemic risk, and, ultimately, the impact on the rest of the economy were just as real in Europe as they were in the US (Ciro, 2012).

The responses to the credit crisis varied geographically - there were global responses such as the common approaches agreed upon by the G20, as well as specific European, American, Japanese, or Chinese reactions - as well as by government actor within each jurisdiction. In almost real-time, central banks responded by flooding various markets with liquidity and attempting to restore confidence in the financial system. In the short- to medium-term, individual governments responded with fiscal stimulus of their national economies (Chiaramonte, 2018, pp. 90-92). And once the immediate crisis had past, regulators analyzed the systemic problems that had allowed the crisis to occur, in order to draft new rules to prevent such an event from recurring (Ciro, 2012).

For the purposes of this research paper, the most relevant policy response to the crisis - that which has the greatest impact on the current process landscape for European investment banks engaging in proprietary bond trading - is the regulatory framework established in MiFID II and MiFIR. Following the high-level analysis of both the GFC and the regulatory response in the previous chapters, the focus of the research paper will narrow considerably to look at the impact of these events on the bond markets specifically. For the sake of simplicity, the combined regulatory framework of the directive and the regulation will hereafter be referred to as MiFID II, unless a text of the MiFIR regulation is cited directly. The main goals of MiFID II were to make the financial markets more efficient, resilient, and transparent, while at the same time increasing investor protection. The framework is an extension of the basis provided by MiFID I, which entered into force in 2008, just as the financial crisis was intensifying (Comana, et al., 2019).

The overall impact of the MiFID II regulation on European bond markets is that it forces virtually all activity in the secondary market to move to an electronic medium. Regardless of whether an investment firm trades on its own account as a dealer or executes transactions on behalf of a customer, and whether the investment firm is active on a trading venue or in the OTC market, every bond trade must be recorded and reported in a strict technical format. This requirement alone requires that manual processes, such as trading with customers by telephone, be moved to, or at least be supported by, an electronic system. The manual efforts for maintaining regulatory compliance with media gaps between telephone conversations, paper order tickets, emails, and a reporting system would be prohibitively expensive and time-consuming (Temporale, 2015).

\subsection{The Bond Trading Process Landscape}

The process landscape for most investment firms - whether buy-side or sell-side - is built around the trade lifecycle. Regardless of the financial instrument traded, a transaction will have a lifecycle, and certain processes are common to all transactions. The core business processes along the value chain can be divided into three categories, known as front-, middle-, and back office, and each set of processes is supported by a distinct organizational unit or multiple units. Due to the division of functions into a matching organizational structure, the operational units often unofficially take on the names front-, middle-, and back office as well. Within this research paper, the term front-office function or front-office process will be used to describe functions and processes, while front office will refer to the organizational unit. The following chapter will describe the functions of each of these types of processes and organizational units within the context of the proprietary bond trading business of a European investment bank (Baker, 2015).

Front office is comprised of the organizational units that transact directly in the financial market. In the trade lifecycle, front-office functions include the categories pre-execution, trade execution, and trade capture. For an investment bank trading on a proprietary basis, this includes the sub-functions 
disseminating the bank's quoted prices, or simply "quotes", and inventory of bonds, measuring customer interest in trading - either purchasing or selling - based on these quotes, negotiating and agreeing upon the final terms of a transaction - including the notional value, price, and settlement terms - and entering the trade into an internal system or register, so that the bank can record it on its books (Baker, 2015). Middle office is a collection of organizational units that both support and control the activities of front office. In its controlling functions, middle office ensures that trades are booked correctly in the firm's position keeping systems. Once a trade has been booked, a confirmation is sent to the customer, showing all the details of the trade. At the end of the day, a reconciliation report may also be sent to each customer or counterparty, showing a listing of all the transactions that were agreed upon during the day. With the advent of MiFID II, the reporting obligations for investment firms became much more substantial. In addition, middle office is responsible for managing risk. One form of risk that is relevant for all financial instruments is market risk - in other words the risk that the value of a bond, or any other instrument, that the investment firm has purchased or sold - will rise or fall. In order to allow a proper analysis of a dealer's risk, single trades or transactions are grouped together with other transactions in the same financial instrument to show a position. Ensuring that the market prices are available and that the position calculations are performed properly is a function of middle office (Baker, 2015).

Back office is comprised of the organizational units that exchange assets, documentation, and payments with counterparties for the transactions that have been traded by front office. In this regard, back office is the unit of the investment bank or other financial institution that completes the transactions. The main processes in back office for bond trading are settlement, custody, and administration. Back office is therefore sometimes known as the operations department of a financial institution (Baker, 2015).

Settlement is the process by which bonds or other securities that have been purchased by the investment bank are received and those that have been sold are delivered to the counterparties to each trade. Simultaneously, settlement involves the transfer of payment to the bank for sales and to the counterparty for bond purchases. This simultaneous transfer is known as delivery versus payment (DVP) or receipt versus payment (RVP). In order to allow time for middle office to reconcile trades and correct any issues, most trades are settled on $\mathrm{T}+2$. If the bank or a counterparty needs to take delivery faster, a $\mathrm{T}+1$ settlement or even same-day $\mathrm{T}+0$ settlement can be specified. Or if an institution knows that it will first have the bonds in its account later, it may specify settlement on $\mathrm{T}+3$ or later, in order to avoid having a negative position - also known as being short - in the security (Dickinson, 2015).

\subsection{Digital Technologies}

It is important to distinguish digitalization from the related term digitization. Digitization means the transformation of information from an analogue to a digital format. Examples range from photographs or paper documents that are scanned and turned into .pdf files to temperature or voltage readings that are converted to a digital value rather than being measured on an analogue display. Digitalization, on the other hand, is the integration of digital technologies into an existing business model as a means of adding value to the business, either by identifying new revenue-generating opportunities or by increasing the efficiency of business processes that add value (Gartner Glossary, 2021).

Digitization is, therefore, a prerequisite for digitalization. Digitalization can be defined as "the adoption of digital technologies in business and society as well as the associated changes in the connectivity of individuals, organizations, and objects." In the context of the investment bank, the first part of this definition of digitalization as the adoption of digital technologies is, in itself, simple, and the use of an electronic medium to carry out tasks that were previously performed in another medium is also straight forward. Examples include a salesperson speaking to a customer on a telephone being replaced by an electronic RFQ from an MTF, or the physical transfer of securities in a warehouse from one owner to another being replaced by an electronic record at a CSD (Urbach \& Röglinger, 2019).

Any business process executed in an electronic medium creates data. The smallest unit of data in a database is the data item. Data items can be facts, figures, or numbers, such as a trade timestamp, a customer name, or a price, though even a seemingly simple record such as a customer name may be composed of two or more data items, such as a first name and a last name. The data item is the smallest unit of data that still has any meaning on its own. Using the example of a customer name, if the first name of a customer were to be further broken down into its components, all that would remain would be individual letters or other characters of no significance. This means the data item is the customer first name, not the consolidated full customer name and not the individual letters (Teorey, et al., 2010). Taken individually, even pieces of data without any context are meaningless, a pile of partial events and records 
with no relation to each other and no value to an organization that records them. In order to be of any value to a user or an organization, data items must be organized, structured, and processed into information. In a given context and within a proper explanation, it can be invaluable to an organization (Urbach \& Röglinger, 2019).

Database management and queries are based on a specific syntax known as Structured Query Language (SQL). Through SQL, the relational database model is structured into individual tables, with a table corresponding to exactly one type of class in the database model. Individual objects of a class are created as records in a table, with one line, or record, per object. SQL has commands for creating, altering, or deleting complete tables or the records within them. In an approach known as Online Analytical Processing (OLAP), SQL also supports queries from the database, allowing a user to link results from multiple tables based on their attributes and the primary keys that link the object types together in the relational model. OLAP-based tools offer a means of generating SQL-queries across multiple tables of a database. The analytical purposes can be categorized as consolidation, drill-down or cross-referencing (Teorey, et al., 2010).

Most databases have a limited scope, being linked to a specific business application, for which the relational data model has been developed. But a complex organization such as an investment bank will have multiple applications and multiple databases. Even for a narrow scope, such as proprietary bond trading, a database or multiple databases will likely exist for the OMS and TRM, as well as a regulatory reporting system, a reference system for financial instruments, a Customer Relationship Management (CRM) system, and many more applications. Proprietary trading for a different class of financial instrument may use a different OMS and even a different TRM. A user of each individual system may see detailed records of the activity within that system, but if a user wishes to see aggregated activity over multiple systems - for example, in order to examine whether a customer who has purchased bonds from the bank in the previous three months has also traded CDS or equities - it is necessary to query each database separately (Teorey, et al., 2010).

The concept of the data warehouse was created in order to solve this problem. A data warehouse is essentially a large database system with additional functionality. It collects and consolidates data from multiple databases, integrating them into a single system that can be queried by a single user or system. The challenge in creating a data warehouse is both functional and technical. Functionally, a new relational data model must be created that consolidates the classes, attributes, and relationships of each of the component databases. The technical challenge in creating a data warehouse lies in the fact that individual databases may have been created in different programming languages and by different external software vendors. Mapping each database into a common format that can be used in the data warehouse is a time-consuming, but necessary, task before the data warehouse can be created (Wrembel \& Koncilia, 2007).

Once data has been collected and standardized in the data warehouse, there are countless ways by which an algorithm can be used in order to provide insights based on the data, but the individual tasks that datamining algorithms are assigned are often grouped into six distinct categories: classification, clustering, regression analysis, anomaly detection, associative analysis, and summarization (Kotu \& Deshpande, 2014).

A second critical aspect of digitalization is process automation. A process can be defined as "the endto-end work across an enterprise that creates customer value." Business Process Management (BPM) is an integrated system through which an organization analyzes, models, measures, and improves upon the way that it works. A complex process can be built from constituent individual tasks, each executed by a specific actor and in a specific sequence. A process requires inputs, applies a method of work to those inputs, and produces an output. At the start and at the end of every process is a customer, who can be either within or outside to the organization. BPM is an area of study that builds on the intellectual foundation of quality management and statistical control. But whereas quality management in its early development was based on the assumption that processes are sound and that quality defects were the result of poor execution, BPM focuses on the design of the processes themselves and determines how these can lead to high- or low-quality services or products (Hammer, 2010).

The key to process automation is in the integration of data, process design, and application software, where the processes are executed. Integration can be through a so-called business process automation engine, the two main components of which control the data integration and the process integration, respectively. Once business processes have been modelled in detail, a workflow engine delegates individual tasks to the various applications that contain the individual tasks that are involved in a process. 
For an investment bank these applications would include the OMS, CRM, and TRM (Kirchmer \& Scheer, 2004).

The move towards service-oriented architecture (SOA) offers a wide range of possibilities for interapplication process automation. SaaS reduces complex workflows and functionality in an application into individual processes that have clearly defined inputs and outputs, and which can be called upon via standard interfaces. These interfaces are often web services that can be reached by any system that can call the IP address. This reduces the need for maintaining complex interfaces, and it reduces the barriers for systems communicating with each other. Individual functions, or services, can be automated in a single application, importing an input file or data and exporting an output file or data automatically, if certain conditions are met. If multiple functions can be placed together in a sequence, the entire process chain can be automated, with the output of each process automatically providing the input for the next process, regardless of whether it takes place in the same or a different application. But the foundation of this automation is a set of clearly defined processes, with the conditions for each decision in the process chain clearly defined. An automation of even partial processes without having clearly defined end-toend processes risks chaos, as human decision makers are quickly removed from the workflow. Even with well-defined processes, the automation of the process chain also increases the importance of a close cooperation between IT and business. Sufficient testing of all possible use cases in a simulation environment is also critical before any automated process is activated in a production environment with real data and real use cases (Kirchmer \& Scheer, 2004).

Within many organizations, the prerequisites for a highly automated, transparent workflow are likely to be, at best, present only in certain organizational units or in certain IT applications. Core processes, which are essential to the success of an organization, might be defined clearly and maintained in a BPM system. But there are also likely organizational units that have few to no processes clearly defined, let alone maintained in a BPM system. Nor do most organizations have unlimited funding or resources for IT, and there are likely to be disparate legacy software applications of different ages, some of which are likely to have obsolete process workflows or non-standard interfaces (Weingarth \& Hagenschulte, 2019).

Under such circumstances, many organizations may be tempted to focus on consolidating their IT landscape on a pre-automated level of capability before tackling a move to SOA, Web Services, or process automation. But many proponents of digitalization regard this approach - first consolidation, then digitalization - as a flawed strategy, because the pre-digitalization starting point does not have to be perfect, and the digitalization of business processes does not have to happen all at once. Even a partial migration of legacy systems to an open architecture, including data integration and microservices, and automated processes is likely to have both immediate and follow-on benefits. The immediate advantages include more efficient processes for the organizational units that are able to clearly define their business processes and migrate them to SOA-based applications. The follow-on benefits include reducing the cost of maintaining legacy systems, freeing up budget and resources for further digitalization projects, and reducing the complexity of any future system migrations. For risk-averse industries, such as finance, a staggered implementation has the advantage of reducing risk. An organization such as an investment bank can identify core functions where it is not willing to risk a disruption to its core services, and these functions can be treated as the innovation "slow lane". Other functions with less critical functionality may be tapped to be part of an earlier digitalization proof-of-concept. This approach also shows initial successes, which help convince management and employees alike that there are benefits to the initiatives (Weingarth \& Hagenschulte, 2019).

\section{Original Research}

The primary research upon which this paper is based built upon the theory discussed in chapter 2 . The research design was determined by the research questions. These are of an exploratory nature, therefore a qualitative research design was considered to be the most appropriate to answer the questions posed above. The first research question asks which KPIs can be used to measure performance. Though many organizations and organizational units use KPIs to quantify their own performance, this should not be confused with the research itself. Though the KPIs themselves deliver quantitative results, the determination of which KPIs to use is a qualitative question, as there is no single correct answer, and the results may vary between organizations. Similarly, the determination of which processes can be optimized by applying digital technologies - as stated in the second research question - is a qualitative 
one. And in the third research question, a determination of what can reasonably expected as a result is a matter of opinion, which must be considered qualitative, though the answers may include a quantitative assessment.

Within the framework of a qualitative research design, expert interviews were considered to be the most appropriate research method. The topic that was researched is highly specific, and only a relatively small number of interview subjects was considered qualified to provide an assessment of these processes, the data needed to support them, and the prospects of automating the processes. Group interviews or focus groups were, therefore, not considered appropriate. Rather, individual interviews with experts from each core area of the process landscape - front, middle, and back office - of the bank, as well as with IT experts who are in a position to support the core processes, were used. The six interviewees were selected as follows: a department head in fixed income trading, a senior fixed income trader, a senior expert within back office, a senior expert within middle office, a department head in IT strategy, and a department head in IT markets. Cooperation in conducting interviews for the research presented in this paper was obtained from a tier three European bank, along with a subsidiary IT service provider, as well as many of the individual experts of both entities. This cooperation was granted on the condition of anonymity, both for the bank itself and for the individuals who agreed to be interviewed. Furthermore, it was agreed that the full details of the interviews were not to be published for a period of three years. Only the results of the interviews in general terms are included below. The information uncovered in the six interviews was deemed sufficient for answering the research questions. These will be addressed in the sequence that they were posed.

The first research questions asked: Beyond the profit or loss in an organization's bottom line, which KPIs can be used to measure the performance of a bank's proprietary bond trading organizational units?

Numerous KPIs were defined for each bond trading operational area, as well as in the supporting IT service provider. Front office experts affirmed that P\&L is, indeed, the most important KPI for a bond dealer to measure, but there are other KPIs that have a significant contribution - either directly or indirectly - to P\&L. These are quote response time, the percentage of customer quotes left to expire unanswered by the bank's traders, the dealer's market share, the hit ratio, and the distance between the traded price and the covered price. In middle office and back office, the STP rate and average trade passthrough time were defined as the most important KPIs, with software configuration effort and passthrough time, especially in conjunction with the setup of new customers' static data in internal systems, being other important values to measure. For an IT service provider that supports a bond trading bank via its infrastructure and software applications, the picture is somewhat more complex. An IT service provider must share the KPIs of the business that it supports. But in designing an IT strategy, the IT organization must also measure its cost-efficiency, time to market for new products, and stability of its systems, in order to assess its performance.

The second research question asked whether the KPIs uncovered in the research can be assessed in the context of digitalization: Which processes or subprocesses in front, middle, and back office, as well as in IT, can be optimized by the application of digital technologies?

The research showed numerous business processes in all functional areas of a bank's bond trading operations that could be improved through the application of digitalization technologies. In front office, the entire scope of the bank's interactions with customers can be improved with the help of digitalization. A mix between process automation and data integration is required to achieve balance. The bank can use process automation software to automatically provide customers with a price in response to a customer RFQ. It can, as an alternative, allow its traders to continue to manually provide customers with human-generated prices, but it can simplify this task by integrating the necessary information for a trader in a single application. Once a trade is executed by the bank's traders, an automated chain of STP processes is initiated, which capture the trade and import it from the external trading venue to the bank's internal TRM or position keeping system. Within middle office and back office, STP process chains continue to reconcile, enrich, report, and settle each trade that has been imported. Though the baseline of process automation is much higher than in middle office, ever improving technologies allow middle and back office to strive for much higher STP rates. Not only the value creating business processes for handling individual trades, but also some of the support processes required for setting up new static data for customers and instruments can be improved by data integration and business process automation.

There are, however, limitations to which processes can be improved. For many processes that humans can perform with a higher level of quality than an algorithm, or which are too complex for process automation, it is expected that digitalization cannot provide any further improvements. In front office, 
the maintenance of customer relationships is a primarily human activity. In middle office, though STP may be optimized to automatically persist trades from a TRM system to diverse risk or reporting systems, the interpretation of the results within a risk management organizational unit can only be indirectly improved via data integration. And many processes involving the configuration of the software applications, such as the maintenance of SSIs by back office organizational units, are difficult to optimize through automation or data integration. Also, it is difficult to imagine how most processes in IT projects can be automated, since these processes involve analyzing proposed software applications, integrating them with existing business processes, and implementing them in the existing IT landscape. These are unique and highly complex tasks that remain the domain of human analysts. One area that can be automated to some extent is software testing, though the parameterization of automated tests must be performed by humans, and such processes as testing in software projects are highly variable and would not apply equally to all banks.

The third research question asked what impact digitalization would have in terms of improved KPIs: What is a reasonable expectation for the impact on the KPIs through their application?

The research was able to answer this question for most of the KPIs that were identified. Some KPIs in front office, such as market share, hit ratio, and distance to cover, are dependent on multiple independent variables, not only internally within the bank but also externally at competing banks or in combination with customer behavior. This makes it difficult to assess the impact of an increase process automation or data integration in isolation. Other KPIs, such as quote response time or quote requests expired in front office, or the STP rate in middle office or back office, depend only on internal independent variables within a single bank.

The research also demonstrates that there is a difference between the theoretical limit that can be achieved for a KPI through the implementation of digital technologies and the practical limit. In many cases, there are limiting factors that make it neither practical nor desirable for a bank to reach the theoretical limit for a KPI. But beyond answering the research questions directly, the qualitative opinions provided by the experts in the interviews that were conducted allow for the definition of a roadmap for how a bank should go about digitalizing its software applications, in order to optimize its bond trading business. Upon this basis, a hypothetical digitalization roadmap will be defined in the following chapter.

\section{Conclusion}

The research provides strong evidence that digital technology - in the form of both individual software applications that can automate business processes, as well as in system architectures that support integrated data flow between multiple systems - can be used to significantly improve the performance of all aspects of a bank's bond trading operations. Furthermore, it strongly suggests that, though the digitalization implementation will vary between banks, depending on their starting situation, size, resources, strategy, and other variables, a global digitalization roadmap can nevertheless be produced.

But what form should such a roadmap take? Is it realistic to prescribe a list of software applications that any European bank actively trading in the bond market should implement? Or, if not that, perhaps a checklist of processes that should be automated in a specific order, in order to optimize a list of KPIs? Or perhaps a universal list of data fields from each software application in the IT landscape that should be integrated in a data warehouse to be mined by algorithms? The answer to each of these proposals is that they are probably not ideal. Instead, a roadmap can be provided in the form of guiding principles. These principles are global in nature and apply to any bank in the process of digitalizing its bond trading business and IT software applications.

The first principle is that a bank must integrate its IT service providers with its business strategy. It makes little sense - and can, indeed, be catastrophic - to develop a business strategy and an IT strategy separately from each other. An IT service provider can strive towards maintaining stable systems, lowering costs, or bringing new products to market in shorter time frames, but it cannot focus on all three goals at once. If a bank is satisfied with its KPIs in front, middle, and back office and wishes to focus on increasing the stability of its systems, it will have to allocate more money towards hardware and personnel for the testing and maintenance of software. It may balance out costs by reducing the pace of new software development or purchases. On the other hand, if a bank wishes to increase its market share by bringing an improved OMS system, which can support more process automation and better data integration, to its traders, it will likely increase its IT costs and decrease the stability of its software applications, at least in the short term. But for an IT service provider to optimize a KPI such as its costs 
on its own without aligning with the strategy of the bank would be to risk crippling the business that it supports.

The second principle is that no KPI should be optimized without considering its impact on others KPIs. It is important for each operational unit - front, middle, and back office - to establish its own target KPIs. For front office, it is considered necessary to establish at least some technical capability to provide auto-quotations to customer requests that are received from external trading venues, such as MTFs. This means that for some customer RFQs, the target level for the KPI quote response time approaches zero, though practically it will be 100 to $200 \mathrm{~ms}$. But for a trading unit as a whole, the average quote response time is a far more significant factor. Any front office organizational unit that purchases the license for an externally developed OMS could, within a short timeframe, activate auto-quotation for all customer RFQs, bringing its average quote response time to nearly zero. But the limiting factor, that the automated quotes would be of poor quality and would lead to either decreased hit ratios and lower market share or, if the auto-quotation algorithm were calibrated to be too aggressive, to much higher hit ratios and market share but lower overall profit. Much more appropriate for a bond trading desk is to automate the process of quotation where the quality of the price provided is not a significant factor, allowing humans to provide their own prices manually for the important requests. The limiting factor on automation is business strategy, not IT costs or technology.

But process automation is only part of the story in front office. For that portion of its customer RFQs that a bank chooses to keep in the hands of its human traders, the research shows that it is important to integrate data from various software applications and put this data in front of the human trader in the OMS system, as a means of reducing the workload for the trader and allowing him or her to concentrate on the market conditions and the actions of the customer. At a minimum, this integration should include integration of the OMS with the TRM and any risk management system. This allows a trader to see two important pieces of information: how much of a requested bond is in inventory; and how much the trader is permitted to buy. Checking such details is a prerequisite to the trader performing the task of deciding how aggressive to be in determining a price, but the decision rather than the checks themselves are where the human trader can add value.

In middle office and back office, the picture is somewhat different. An STP rate of 100 percent is desirable for both organizational units, at least as far as the processing of individual trades is concerned. Rather than the low quality of the outcome in an automated process, the costs are the limiting factor. A bank cannot and should not blindly pursue an STP rate of 100 percent, even if it is a target. Far more important is the KPI, which must be assessed as part of any digitalization project in middle or back office, increase in STP rate per unit of money spent during the software implementation and during operations afterwards. The organization must also understand what it hopes to get out of the increased STP rate. Are there important customers that the bank wishes to gain or prevent from leaving, for which an increase from 92 percent STP to 96 percent STP is a deciding factor? Can so many personnel costs be saved in back office from reducing the STP breaks that require human intervention from 8 percent to 4 or even 2 percent? Another possibility would be that the bank could modernize its IT system landscape by replacing multiple legacy software applications with a new application, which might reduce the operational costs and increase the STP rate simultaneously. Such a project would be a quick win and should be funded as a high priority digitalization measure.

A third principle that a bank must consider when determining which processes to automate is that humans should remain in the process chain wherever they can add more value than a machine. This principle was illustrated above in the example of front office splitting the task of responding to customer RFQs between humans and automated software. In middle and back office, it is also necessary to recognize that in spite of the target of 100 percent STP, there is still a significant role for humans in optimizing processes, calibrating the parameters of automated processes, reviewing risks, and adjusting business strategy. Data integration or even data analysis with the assistance of algorithms may be useful tools in assisting humans with these tasks, but it is important to understand that not every task in middle and back office should be automated.

The key to choosing the right digitalization initiatives is to apply the combined business and IT strategy to the IT service portfolio. At a bare minimum, a bank's IT service portfolio for bond trading consists of the OMS, TRM, risk management system, settlement system, reporting systems, interfaces to external data vendors and trading venues, as well as numerous databases or data warehouses along the way. Business priorities should determine one which basis the software applications in the service portfolio are analyzed and selected for overhaul or improvement. If the bank is satisfied with its current 
catalogue of services that it draws from the IT service portfolio but wishes to reduce its costs, then the most expensive applications in the IT landscape should be analyzed and an assessment done whether these can be replaced through a cheaper alternative without sacrificing system stability or functional scope.

A highly effective, accessible, and digital-ready IT landscape should be achieved using software applications that are cloud ready and which have open APIs to allow standard service calls from multiple systems. This allows data integration to be achieved on a more fundamental level than simply exporting the data of multiple systems into the same data warehouse and building a dashboard to view it all. There are, however, multiple paths to achieving such an open and flexible architecture. There is no predetermined best-fit regarding the choice of whether to break down all of its software applications into microservices or rather to use monolithic, purpose-built applications. A bank must understand its strengths and weaknesses, as well as those of its IT service provider, when weighing these two alternatives. If an organization has a high level of discipline in its process management, as well as a good working relationship with supporting IT analysts who understand the fundamentals of the bank's bond trading business, it may be able to handle the added complexity of managing every business process, particularly in middle and back office, as a series of microprocesses. In doing so, it may increase the flexibility of its applications and decrease the time to market for new services. But a bank that is lacking robust control, documentation, and measurement of its business processes, or which has only rudimentary project management capabilities, will likely find that external software vendors have outof-the-box or customizable solutions that fit its needs. In short, there are several paths to the same goal. A bank, together with its IT service provider, must understand its strategic goals and operational strengths before it chooses a path.

One weakness of the hypothesis is that the research was conducted under the condition of anonymity, not only for the individual experts who agreed to be interviewed, but also regarding individual systems, projects, and many more critical details regarding the bond trading business operated by the bank of the operational experts and supported by the IT experts. The KPIs, digitalization measures, definitions, workflows, and principles that were extracted from the information provided have not lost any of their validity on account of the anonymity. But many illustrative examples - such as those pertaining to how specific software applications are integrated to process and save data from actual trades or related to how a specific pricing algorithm in front office provides high quality prices under some circumstances but is not optimal in other situations - would have provided the reader with detailed and concrete examples of the theory in action.

On the other hand, without anonymity for the bank and its IT service provider, the danger would have been much greater that the research paper might have lost its general validity for all banks involved in the European bond market. Too many examples of specific IT systems, concrete business processes, and detailed solutions to problems at the bank would have risked turning the research paper into project work for a single organization. In other words, the weakness also has a positive aspect. Another weakness is that the experts who were interviewed were all drawn from a single European bank and a single IT service provider. A cross-section of opinions from experts in all three operational areas from multiple banks of different sizes, located in different European countries, and with different segments of the European bond market as the central focus of their bond trading business would have added different perspectives. This would have served to verify the information already obtained from the research, and it would have increased the confidence in the conclusions that were drawn.

The most interesting point for further research is in the operational area front office. Though algorithms for the generation of prices are highly sophisticated in the equity markets, in the bond market they are still in their infancy. As Expert F noted, the market may dictate completely different behavior from European bond dealers in even one year's time. A detailed analysis of how banks use their own proprietary, historical data to train algorithms and generate prices that will give them a competitive advantage over the competition would be a large enough topic that it would require its own dedicated research paper. The scope of this research would be much narrower, yet deeper than the current research paper, focusing on the individual factors that contribute to market price in a scenario where humans and machines increasingly support each other and, at the same time, compete. But whether such a research paper would be possible in an academic setting is, at best, doubtful. Academic research requires transparency, and for a bank to allow the internal workings of its price-generating algorithms to be published in a transparent setting would be to put itself at a disadvantage versus its competition that 
would be difficult to overcome. As stated by Expert F, as soon as the competition knows what you are doing, you need to change it.

Such a competitive disincentive to transparency does not exist in middle or back office, where banks strive for similar, optimized STP-based business processes. One bank being more efficient and having a high STP rate does not directly cause a competitor to lose business. Further research in the areas middle and back office could be conducted across multiple banks, in order to determine whether microservices or monolithic software applications, such as an all-encompassing TRM system, offers better outcomes in terms of the KPIs named. On the condition of anonymity such research might theoretically be permitted.

\section{References}

[1] Baker, R. (2015). The Trade Lifecycle: Behind the Scenes of the Trading Process (2 ed.). Cornwall: Wiley.

[2] Chiaramonte, L. (2018). Bank Liquidity and the Global Financial Crisis: The Causes and Implications of Regulatory Reform. Cham, Switzerland: Palgrave Macmillan.

[3] Ciro, T. (2012). The Global Financial Crisis: Triggers, Responses and Aftermath (1. ed.). London: Taylor and Francis.

[4] Comana, M., Previtali, D., \& Bellardini, L. (2019). The MiFID II Framework: How the New Standards are Reshaping the Investment Industry (1. ed.). Cham: Springer.

[5] Covas, F., Rezende, M., \& Vojtech, C. (2015). FEDS Notes: Why Are Net Interest Margins of Large Banks So Compressed? Retrieved February 15, 2021, from https://www.federalreserve.gov/econresdata/notes/feds-notes/2015/why-are-net-interest-margins-oflarge-banks-so-compressed-20151005.html

[6] Dean, J. (2014). Big Data, Data Mining, and Machine Learning: Value Creation for Business (1 ed.). Hoboken: John Wiley \& Sons.

[7] Dickinson, K. (2015). Financial Markets Operations Management (1. ed.). Cornwall: Wiley.

[8] European Securities and Market Authority. (2020). MiFID II. Retrieved December 30, 2020 from https://www.esma.europa.eu/policy-rules/mifid-ii-and-mifir/

[9] Francisco, R. (2012). Finance for Academics: A Guide to Investment for Income. Lawrence, USA: Springer.

[10] Gartner Glossary. (2021, April 20). Digitalization. Retrieved from Gartner IT Glossary: https://www.gartner.com/en/information-technology/glossary/digitalization

[11] Hammer, M. (2010). What is Business Process Management. In J. vom Brocke, \& M. Rosemann (Eds.), Handbook on Business Process Management 1: Introduction, Methods, and Information Systems (pp. 3-16). Heidelberg: Springer.

[12] Ho, T., \& Macris, R. (2003). Dealer Market Structure and Performance. In Y. Amihud, T. Ho, \& R. Schwartz, Market Making and the Changing Structure of the Securities Industry (pp. 41-66). Washington D.C.: BeardBooks.

[13] Iannotta, G. (2010). Investment Banking: A Guide to Underwriting and Advisory Services. Milan: Springer.

[14] JP Morgan Chase \& Co. (2020). Annual Report 2019. New York: JP Morgan Chase \& Co.

[15] Kirchmer, M., \& Scheer, A.-W. (2004). Business Process Automation - Combining Best and Next Practices. In A.-W. Scheer, F. Abolhassan, W. Jost, \& M. Kirchmer (Eds.), Business Process Automation (1. ed., pp. 1-16). Heidelberg: Springer-Verlag.

[16] Kotu, V., \& Deshpande, B. (2014). Predictive Analystics and Data Mining: Concepts and Practice with RapidMiner (1. ed.). Waltham: Elsevier.

[17] Laffan, B. (2015). Framing the Crisis, Defining the Problems: Decoding the Euro Area Crisis. In C. Schweiger, \& J. Magone (Eds.), The Effects of the Eurozone Sovereign Debt Crisis (1 ed., pp. 266285). New York: Routledge.

[18] Mayer, M., \& Karpis, A. (1993). Nightmare on Wall Stree: Salomon Brothers and the Corruption of the Marketplace. New York: Simon \& Schuster.

[19] Mobius, M. (2012). Bonds: An Introduction to the Core Concepts. New York: John Wiley \& Sons. [20] Schapiro, M. (2010). Testimony Concerning the Lehman Brothers Examiner's Report by Chairman Mary L. Schapiro, SEC, Before the House Financial Services Committee. Washington DC: US Securities and Exchange Commission.

[21] Temporale, R. (2015). Europäische Finanzmarktregulierung: Handbuch zu EMIR, MiFID II / 
MiFIR, PRIIPs, MAD / MAR, OTC-Derivaten und Hochfrequenzhandel (1. ed.). Stuttgart: SchäfferPoeschel Verlag.

[22] Teorey, T., Lightstone, S., \& Nadeau, T. (2010). Database Modeling and Design: Logical Design (4. ed.). San Francisco: Morgan Kaufmann.

[23] Tyce, J., \& Tang, L. (2020). European banks' next wave of cost-cutting begins. Retrieved February 15, 2021, from https://www.bloomberg.com/professional/blog/european-banks-next-wave-of-costcutting-begins/

[24] Urbach, N., \& Röglinger, M. (2019). Introduction to Digitalization Cases: How Organizations Rethink Their Business for the Digital Age. In N. Urbach, \& M. Röglinger (Eds.), Digitalization Cases: How Organizations Rethink Their Business for the Digital Age (pp. 1-14). Cham: Springer.

[25] Weingarth, J., \& Hagenschulte, J. S. (2019). Building a Digitally Enabled Future: An Insurance Industry Case Study on Digitalization. In N. Urbach, \& M. Röglinger (Eds.), Digitalization Cases: How Organizations Rethink Their Businesses for the Digital Age (pp. 249-272). Cham: Springer.

[26] Wrembel, R., \& Koncilia, C. (2007). Data Warehouses and OLAP: Concepts, Architectures and Solutions (1. ed.). Hershey: IRM Press. 